\title{
O Direito fundamental à segurança Social e seu panorama na ordem constitucional brasileira
}

\section{ThE FUNDAMENTAL RIGHT TO SOCIAL SECURITY AND ITS VIEW ON THE BRAZILIAN CONSTITUTIONAL ORDER}

\author{
* Osvaldo Ferreira de Carvalho
}

Resumo: Este artigo versa sobre o direito fundamental à segurança social e seu panorama na ordem constitucional brasileira, de modo que a segurança social se caracterizar como um sistema de proteção e justiça social. Neste estudo, sustentase que a segurança social é um direito fundamental público subjetivo, irrenunciável, inalienável e intransmissível. Pretendese, ainda, elucidar que em nosso sistema jurídico-constitucional, a justiça social é o fim da Ordem Social e se exprime na equânime distribuição dos benefícios sociais para quantos deles necessitem e que a segurança social é o modelo protetivo que se destina a institucionalizar os seus preceitos. Além disso, indica-se os princípios regentes da segurança social no plano constitucional.

Palavras-chaves: Segurança social. Direito fundamental. Princípios.

Abstract: This article focus on the fundamental right to social security and its view in the Brazilian constitutional order, so that social security is characterized as a system of protection and social justice. In this study, support that social security is a subjective public fundamental right, inalienable, indivisible and non-transferable. The purpose this article is to also clarify that in our legal and constitutional system, social justice is the end of Social Order and is expressed in the equitable distribution of social benefits for those who need them and social security is the protective model that is designed to institutionalize its precepts. In addition, it is indicated the governing principles of social security at the constitutional level.

* Doutorando em Direito pela Universidade de Lisboa, Mestre em Direito, Professor universitário nos cursos de Graduação e Pós-Graduação. E-mail: osvaldopesquisador@ gmail.com

Keywords: Social security. Fundamental right. Principles. 


\section{INTRODUÇÃO}

O debate acerca da segurança social tem alcançado mais abundante receptividade no meio acadêmico. A segurança social foi erigida à categoria de direito fundamental no elenco dos direitos fundamentais sociais do artigo $6^{\circ}$ da Constituição brasileira de 1988. Ademais, tratou-se de consagrar em seu texto um regime constitucional da segurança social (ou seguridade social), esta última expressão foi a escolhida pelo constituinte brasileiro, ao abarcar os três eixos: saúde, previdência social e assistência social. Neste artigo vamos privilegiar a designativo segurança social por ser o mais adequado uso no plano técnicolinguístico.

Este artigo objetiva, pois, traçar um panorama o mais abrangente possível quanto à formatação da segurança social pelo regime constitucional brasileiro que busca atender a padrões adequados de bem-estar social e, acima de tudo, com o escopo de assegurar a todos uma vida digna e saudável.

O direito à segurança social constitui um típico direito social de natureza positiva cuja realização exige o fornecimento de prestações por parte do Estado, impondo-lhe verdadeiras obrigações de fazer e de prestar. O direito à segurança social impede a sua revogação, mas não a sua reforma, e confere a todas as pessoas o direito aos benefícios assegurados pelo sistema.

A segurança social como política social é método de economia coletiva. Sendo método de economia coletiva, a comunidade é chamada a fazer um pacto técnico-econômico em que a solidariedade social é a que serve de guia.

Assim, procurar-se-á delinear a ideia de segurança social coligada com a concepção de solidariedade, bem como os principais princípios regentes da segurança social.

\section{A IDEIA DE SEGURANÇA SOCIAL}

Com o final da Segunda Guerra, um novel conceito de proteção social surgiu com a instituição do Estado de Bem-Estar (Welfare State): o conceito de segurança social.

O conceito de segurança social como hoje concebemos lança suas raízes no Relatório Beveridge apresentado ao Parlamento Britânico em novembro de 1942 por Sir. William Henry Beveridge. Há dois modelos de proteção social. O continental (alemão de 1883) e o atlântico (inglês de 1942)

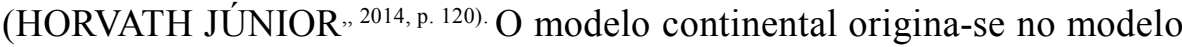


alemão de Bismarck e tem como característica a contributividade. Já o modelo atlântico de proteção social lança raízes mais remotas na política do Presidente Roosevelt ao implementar a política New Deal fulcrado na filosofia do welfare state.

A segurança social como sistema visa ao alcance do bem-estar e justiça sociais. $\mathrm{O}$ direito à segurança social constitui um dos mais elementares direitos à sobrevivência e à existência condigna (CANOTILHO; MOREIRA, 2007, p. 814). A segurança social é um sistema em que o Estado garante a libertação da necessidade. ${ }^{1}$ A segurança social é a forma que o Estado tem de assegurar aos cidadãos uma tutela de base que ampara suas necessidades essenciais.

No quadro do sistema jurídico em geral e também do direito à segurança social, há um princípio que serve de pedra angular: a dignidade da pessoa humana (LOUREIRO, 2008, p. 192). Tal princípio não é uma mera abstração, não representa uma pura idealidade, visto que sua qualidade de princípio jurídico vigora em regra mediante normas positivas e realiza-se por consenso social que suscita ao se projetar "[...] na consciência jurídica constituinte da comunidade” (ANDRADE, 2012, p. 48).

A garantia que assegura a satisfação das necessidades essenciais faz nascer, para os integrantes da sociedade, o direito público subjetivo oponível contra o Estado quando este não cumpre as garantias fixadas constitucionalmente com o nítido objetivo de assegurar a todos uma vida digna e saudável. Tal panorama guarda sintonia com o Direito Internacional dos Direitos Humanos, mais precisamente com a Declaração Universal dos Direitos Humanos de 1948, ${ }^{2}$ o Pacto Internacional dos Direitos Econômicos, Sociais e Culturais de $1966,{ }^{3}$ assim como, no âmbito do Sistema Regional Interamericano, a Declaração Americana de Direitos e Deveres do Homem $(1948)^{4}$ e o Protocolo de San Salvador Adicional à Convenção Americana sobre Direitos Humanos em Matéria de Direitos Econômicos Sociais e Culturais de $1988 .^{5}$

O direito à segurança social é público subjetivo, irrenunciável, inalienável e intransmissível. Para o professor Wagner Balera (2000, p. 11), o Sistema

\footnotetext{
${ }^{1} \mathrm{O}$ estado de necessidade, em termos gerais, pode ser definido como um estado de insuficiência do indivíduo, dentro de seu meio social ou de carência de bens e serviços suficientes para uma digna subsistência.

2 Artigo 25, n. 1.

3 Artigo $9^{\circ}$.

${ }^{4}$ Artigo 16.

5 Artigo $9^{\circ}$ - Direito à Previdência Social.
} 
Nacional de Seguridade (Segurança) Social, do ponto de vista sistemático, visa à implementação do ideal estágio de bem-estar e da justiça sócias e, para a construção desta estrutura, o legislador adotou técnicas de seguro social (previdência social) e de seguro privado (previdência complementar).

Logo, para Wladimir Novaes Martinez (2010, p. 292), a seguridade (segurança) social constitui técnica de proteção social ao abarcar "[...] um completo plano de benefícios, seletivo e distributivo, arrolando prestações assistenciárias e serviços sociais custeados globalmente por toda a sociedade de consumidores, mediante exações tributárias ou não”. O objetivo principal continua sendo o indivíduo socialmente tido, não se estendendo ao seu patrimônio.

\subsection{Do direito à saúde}

Saúde como direito fundamental de todos nada mais é do que uma forma, meio, instrumento de se garantir uma existência de vida digna aos integrantes da comunidade local e global.

Para além da vinculação com o direito à vida, o direito à saúde (aqui considerado em sentido amplo) encontra-se umbilicalmente atrelado à proteção da integridade física (corporal e psíquica) do ser humano, igualmente posições jurídicas de fundamentalidade indiscutível (SARLET; MARINONI; MITIDIERO, 2014, p. 592).

Já se vislumbra a razão pela qual, precisamente no caso do direito à saúde, merece tanto destaque a circunstância - comum, em termos gerais, porém com significativas variações, a outros direitos fundamentais (como é o caso da moradia) - tão bem percebida por João Carlos Loureiro (2006, p. 666), no sentido de que a saúde é um bem fortemente marcado pela interdependência com outros bens e direitos fundamentais, apresentando, de tal sorte, "[...] zonas de sobreposição com esferas que são autonomamente protegidas”, como é o caso da vida, integridade física e psíquica, privacidade, educação, ambiente, moradia, alimentação e trabalho (LOUREIRO, 2006, p. 666).

O conceito inclusivo de saúde expressa a organização social e econômica do país, o que situa nitidamente e intencionalmente o direito à saúde como elemento basilar da construção da cidadania brasileira.

A Organização Mundial da Saúde (OMS) conceitua saúde como o estado de completo bem-estar físico, social e mental, e não simplesmente a ausência de dores ou enfermidades. 
A saúde apresenta ainda uma dimensão coletiva e individual. A dimensão coletiva é caracterizada pelo estabelecimento de marcos mínimos de defesa e fiscalização da saúde pública (controle sanitário dos alimentos e produtos de consumo humano, controle na produção de medicamentos etc.). Nessa dimensão, o conceito de medicina social, é essencialmente ativa e dirigida, e tem por objetivo não apenas a recuperação biológica dos doentes, mas a manutenção e a preservação do estado de saúde satisfatório em toda a população.

Por sua vez, a dimensão individual abarca o enfoque preventivo e reparador (ou curativo). Preceitua o artigo 196 da CF/1988 o seguinte: “A saúde é direito de todos e dever do Estado, garantido mediante políticas sociais e econômicas que visem à redução do risco de doença e de outros agravos e ao acesso universal e igualitário às ações e serviços para sua promoção, proteção e recuperação".

O artigo 196 da Constituição garante o acesso universal e igualitário às ações e serviços de saúde. Veicula, a bem do rigor, princípios de observância obrigatória pelo administrador. O princípio da universalidade indica que todo ser humano ante sua condição humana inerente tem direito e acesso às prestações de saúde. Observando, todavia, sempre os limites e parâmetros do princípio federativo que veda tratamento diferenciado aos integrantes da sociedade com fulcro no artigo 19, inciso III da Constituição Federal.

Além disso, só o acesso igualitário assegura a correta distribuição dos recursos públicos na área de saúde, promovendo, pois, a equidade no sistema. Em resumo, a garantia do direito à vida traz como primeiro pressuposto a efetividade do direito constitucional do direito à saúde.

O direito à saúde não é algo de secundário ou supérfluo, conforme lição de Ana Paula de Barcellos (2008, p. 825), mas compreende, por seu turno, uma posição subjetiva vinculada à satisfação de uma necessidade vital, pressuposto essencial da dignidade humana.

\subsection{Do direito à previdência social}

A previdência social originou-se das lutas por melhores condições de trabalho as quais resultaram em diferentes sistemas protetivos, de acordo com as situações de cada indivíduo envolvido. Alguns limitaram a proteção ao necessário à sobrevivência, enquanto outros foram além, buscando implementar até a substituição plena da remuneração. Tais variações colocam em destaque as diferentes estruturas dos sistemas de proteção. Basicamente, todos pretendiam 
uma previdência social como garantia, ao menos, do mínimo vital, de modo viável financeiramente (IBRAHIM, 2008, p. 1054).

A previdência social, no direito positivo brasileiro, é fixada como componente da seguridade social, haja vista a previsão do artigo 194 da Constituição. Da mesma forma, é tradicionalmente apontada como direito fundamental de segunda dimensão (MENDES; BRANCO, 2014, p. 137-138), configurando garantia positiva típica do Estado Social. ${ }^{6}$ A previdência social é direito social consagrada no artigo $6^{\circ}$ da Constituição brasileira, geograficamente localizada dentro do título Dos Direitos e Garantias Fundamentais. A jusfundamentalidade dos direitos sociais, como é o caso da previdência social, é consequência inequívoca da elevação da dignidade da pessoa humana à centralidade do ordenamento jurídico.

Na passagem do Estado Liberal para o Estado Social, o Estado empenhase, então, consciente e deliberadamente, no processo produtivo, na redistribuição do produto social e na direção ou mesmo planificação do processo econômico. A justiça social e a prossecução da igualdade material - e não já apenas da igualdade perante a lei - são elevadas a fins essenciais do Estado, que assim se afirma como Estado Social (NOVAIS, 2004, p. 31).

Por qualquer setor dogmático, desde o liberalismo libertário, até as versões comunitárias de sociedade, passando pelo procedimentalismo habermasiano, os direitos sociais, e a previdência social em particular, ocupam lugar de relevo, como instrumentos de garantia da liberdade real, da vida ordenada e da democracia. O seguro social é o meio capaz de materializar a necessária e possível integração entre liberdade e igualdade (IBRAHIM, 2008, p. 1062).

O mundo ocidental tem adotado, de modo contundente, uma predileção pelo modelo de seguro social, estabelecendo um custeio específico, com base nas remunerações e benefícios fixados a partir daquelas, limitando-se a ação governamental à manutenção da vida digna.

Um sistema previdenciário eficaz, em conjunto com outras ações sociais, não deve limitar-se à garantia do mínimo vital, mas atender aos riscos sociais crescentes em uma sociedade pós-moderna, com a garantia de uma remuneração compatível e inclusão social efetiva; o sistema previdenciário,

\footnotetext{
${ }^{6}$ O Estado Social de Direito, também denominado de Estado do Bem-Estar, distingue-se justamente por ter avocado para si a tarefa de realização da justiça social, de tal modo que, juntamente com os direitos sociais, pode ser rotulado ao mesmo tempo produto, complemento, corretivo e limite do Estado Liberal de Direito e dos clássicos direitos de defesa de matriz liberal-burguesa. SARLET, 2007 , p. 235.
} 
repita-se, não busca tão somente a manutenção de um mínimo de sobrevivência, mas algum valor que permita ao segurado uma vida digna.

De todo modo, a previdência social ao buscar assegurar a cada um dos integrantes do universo de protegidos o mínimo essencial para a vida, ela vai além da função protetiva. Pouco refletido é o papel igualmente relevante de instrumento do desenvolvimento econômico e social, o que é desejável em qualquer concepção de Estado no mundo ocidental. Não obstante as vantagens já visíveis da globalização, estas não produziram o desenvolvimento sustentável ou a redução das desigualdades sociais. Em muitos casos, a globalização apenas serviu para extremar as desigualdades, sobretudo entre comunidades mais bem amparadas, em detrimento de países em desenvolvimento.

A política de proteção social deve deixar de ser vista como um gargalo ao crescimento econômico, mas, sim, como verdadeiro pressuposto para a construção de uma sociedade livre, justa e solidária.

\subsection{Do direito à assistência social}

A assistência social é direito do cidadão e dever do Estado, é política de segurança social não contributiva que provê os mínimos sociais. É concretizada mediante um conjunto integrado de ações de iniciativa pública e da sociedade para garantir o atendimento às necessidades básicas.

Quanto ao regime constitucional de assistência social ou assistência aos desamparados, configura-se como a expressão máxima do princípio da solidariedade e mesmo do respeito à dignidade da pessoa humana, porquanto representa proteção político-jurídica especial destinada a indivíduos e grupos sociais vulneráveis ou necessitados (SARLET; MARINONI; MITIDIERO, 2014, p. 623).

O artigo 203 da Constituição Federal de 1988 preceitua que "a assistência social será prestada a quem dela necessitar, independentemente de contribuição à seguridade social e tem por objetivos: I - a proteção à família, à maternidade, à infância, à adolescência e à velhice; II - o amparo às crianças e adolescentes carentes; III - a promoção da integração ao mercado de trabalho; IV - a habilitação e reabilitação das pessoas portadoras de deficiência e a promoção de sua integração à vida comunitária; V - a garantia de um salário mínimo de benefício mensal à pessoa portadora de deficiência e ao idoso que comprovem não possuir meios de prover à própria manutenção ou de tê-la provida por sua família, conforme dispuser a lei”. 
Os sujeitos protegidos são todos aqueles que não possuem renda para enfrentar a sua própria subsistência, nem família que os ampare, ou seja, pobres, na acepção jurídica do termo.

Além disso, como destacado no texto constitucional, a obrigação estatal de prestar assistência social independe de contribuição à seguridade social, daí o caráter solidário e redistributivo de tal prática.

A primeira manifestação institucionalizada de assistência social no mundo é comumente atribuída a uma lei inglesa de 1601, a Lei dos Pobres (Poor Law) (PEDRO, 2002, p. 257).

Na França, a Revolução de 1789 institucionalizou uma nova relação entre o indivíduo e o Estado que contribuiu para a estrutura atual da assistência. Apesar de não ter dado frutos legislativos substanciais, os trabalhos desenvolvidos pelo Comitê de Medicité de L'Assemblée Constituante conferiu traços de originalidade ao assistencialismo, ao reconhecer que a desestruturação das classes sociais estabelecidas no Ancien Régime, o laicismo estatal e a generalização da proteção solidária transmudaram a assistência social de um favor voluntário em direito subjetivo (TAVARES, 2008, p. 1124).

A Constituição Federal de 1988 reuniu as coberturas de previdência, assistência e saúde em um sistema de segurança social, imantando-as com princípios e objetivos comuns (art. 194). Além disso, consolidou a assistência como um conjunto de prestações vinculadas aos princípios básicos fundamentadores do Estado Social e Democrático de Direito, em especial à dignidade da pessoa humana.

A assistência social é um direito fundamental social e representa para o Estado um dever a ser realizado mediante ações diversas que visem a atender às necessidades básicas do indivíduo, em situações críticas da existência humana, tais como a maternidade, infância, adolescência, velhice e para as pessoas que têm limitações físicas.

As prestações de assistência social são destinadas a indivíduos sem condições de prover o próprio sustento de forma permanente ou provisória, independentemente se, individualmente, eles contribuem para o sistema de segurança social.

\section{PRINCÍPIOS DA SEGURANÇA SOCIAL}

\subsection{Noção de princípios}

O conceito de princípios, consoante elucida João Carlos Loureiro (2008, 9. 191), assume uma pluralidade de sentidos que vão desde um plano fundacional 
a uma perspectiva metodológica. Sob esse influxo, utilizaremos a formulação princípios $^{7}$ para designar as linhas de força constitucionais que tecem o direito à segurança social.

Os princípios representam a consciência jurídica da sociedade. Possuem a elevada missão de velar pelos valores eternos do homem. Os princípios são alicerces da ciência. Como ideias jurídicas materiais são manifestações especiais da ideia de Direito (HORVATH JÚNIOR, 2014, p. 90).

\subsection{Princípio da solidariedade}

O princípio fundante de um sistema de segurança social é o da solidariedade. O artigo $3^{\circ}$, inciso I, da Constituição Federal de 1988, estabelece que um dos objetivos fundamentais da República Federativa do Brasil é a construção de uma sociedade livre, justa e solidária. O sistema público de segurança social não é exclusivo, coexistindo com formas cooperativas e sociais de solidariedade.

A ideia de solidariedade salienta que o sistema de segurança social pressupõe a responsabilidade coletiva das pessoas e o concurso do Estado para a realização das finalidades do sistema em relação a todos, como garantia da coesão social. Segundo Canotilho e Vital Moreira (2007, p. 815), o princípio da solidariedade comporta várias dimensões: (1) solidariedade nacional, expressa na ideia de transferência de recursos entre os cidadãos; (2) solidariedade laboral, traduzida na existência e funcionamento de mecanismos redistributivos no âmbito de proteção de base profissional; (3) solidariedade intergeracional, assente na combinação de métodos de financiamento em regime de repartição e de capitalização; (4) solidariedade particular pela contribuição de instituições particulares (igrejas, empresas) para os objetivos da segurança social.

Solidariedade social significa a contribuição do universo dos protegidos em benefício da minoria (HORVATH JÚNIOR, 2014, p. 93). Precisamos eliminar a ideia de que os benefícios previdenciários só são concedidos a quem está em situação de impossibilidade de obtenção de recursos para sustento pessoal e de sua família, pois isso não corresponde à totalidade das situações. O sistema protetivo visa amparar necessidades sociais que acarretem a perda ou a diminuição de recursos, bem como situações que provoquem o aumento

\footnotetext{
7 Para Celso Antônio Bandeira de Mello (2013, p. 807-808), princípio é: “[...] mandamento nuclear de um sistema, verdadeiro alicerce dele, disposição fundamental que se irradia sobre diferentes normas compondo-lhes o espírito e servindo de critério para sua exata compreensão e inteligência exatamente por definir a lógica e a racionalidade do sistema normativo, no que lhe confere a tônica e lhe dá sentido harmônico".
} 
de gastos. No momento da contribuição é a sociedade quem contribui; no momento da percepção da prestação, é o indivíduo quem usufrui. Daí vem o pacto de gerações ou princípio da solidariedade entre gerações. Os não necessitados de hoje, contribuintes, serão os necessitados de amanhã, custeados por novos não necessitados que surgem (HORVATH JÚNIOR, 2014, p. 93).

A solidariedade assenta no valor da dignidade. A solidariedade perante os mais vulneráveis é, pois, uma exigência da própria dignidade (MIRANDA; MEDEIROS, 2010, p. 91-92).

\subsection{Princípio da universalidade}

A universalidade é uma característica dos direitos humanos como direitos de todas as pessoas. As prestações decorrentes do sistema de segurança social devem ser destinadas às pessoas que delas necessitem, da forma o mais abrangente possível.

O princípio da universidade afirma que o direito à segurança social é um direito de todos e não restrito aos cidadãos de um específico Estado (LOUREIRO, 2008, p. 201). O princípio da universalidade não somente não consente situações de pessoas sem cobertura social como retira base constitucional àquelas situações em que certas categorias de pessoas, embora cobertas por esquemas privativos de segurança social, se mantêm fora do sistema público, as quais já deviam ter sido integradas no sistema público (CANOTILHO; MOREIRA, 2007, p. 816).

\subsection{Princípio da uniformidade e equivalência dos benefícios e serviços a populações urbanas e rurais}

Por uniformidade, deve-se entender a vedação de proteção social diversa às populações urbanas e rurais. Como vivemos num Estado de segurança social, adota-se o designativo populações urbanas e rurais e não mais trabalhadores urbanos e rurais.

A Constituição brasileira vedou o tratamento desigual para a população urbana e rural, corrigindo distorção histórica. A expressão equivalência fornece dimensão econômica aos serviços prestados e refere-se à igualdade geométrica, à equivalência de proporções. A dimensão da prestação da segurança social é efetivada pela própria sociedade, que define sua participação na elaboração dos planos de segurança social e na elaboração do orçamento próprio.

Por equivalência, deve-se entender a vedação do estabelecimento de critérios diversificados para cálculo dos benefícios previdenciários. A 
uniformidade indica mesmo nível de proteção para as populações urbanas e rurais (HORVATH JÚNIOR, 2014, p.103).

Com o disciplinamento da Constituição Federal de 1988, por meio das Leis $\mathrm{n}^{\text {os }} 8.212 / 91$ e 8.213/91, temos apenas uma previdência social que abrange as populações urbanas e rurais. A intenção constitucional é a eliminação completa de qualquer discriminação entre essas duas populações. Só o tempo nos dirá se foi alcançado este objetivo constitucional.

\subsection{Princípio da seletividade e distributividade na prestação dos benefícios e serviços}

A seletividade é um objetivo de contraposição ao da universalidade. Um ameniza o outro. Enquanto, objetivamente, a universalidade determina que o Estado procure proteger a pessoa da maior gama possível de situações, a seletividade possibilita a ponderação dos critérios de atendimento pela necessidade, dando vantagem aos mais carentes (CUNHA, 1999, p. 39).

A regra da distributividade autoriza a escolha de prestações que, sendo direito comum a todas as pessoas, contemplam de modo mais abrangente os que demonstrem possuir maiores necessidades.

\subsection{Princípio da irredutibilidade do valor dos benefícios}

Este princípio comporta dois aspectos, a saber: o da irredutibilidade nominal e a irredutibilidade real do valor. Segundo Wagner Balera (1998, p. 51), a prestação pecuniária "não pode sofrer modificação nem em sua expressão quantitativa (valor nominal), nem em sua expressão qualitativa (valor real)".

O princípio da irredutibilidade visa manter o poder real de compra, protegendo os benefícios dos efeitos maléficos da inflação.

O que a Constituição Federal assegura é que os benefícios deverão sofrer reajuste periódico que lhe garanta a manutenção, em caráter permanente, do valor real. Agora, se este reajuste será pautado pela adoção de um determinado índice, apurado por determinada instituição, ou mesmo pela periodicidade deste reajuste, são aspectos não definidos pela norma constitucional. Este detalhamento ficou sob o encargo do legislador ordinário.

\subsection{Princípio da equidade na forma de participação no custeio}

O princípio da equidade pode ser entendido como justiça e igualdade na forma de custeio. Decorre da capacidade econômica do contribuinte prevista 
no artigo $145, \S 1^{\circ}$ da Constituição Federal. O princípio da equidade na forma de participação no custeio possui um plus especializante perante o princípio da capacidade contributiva, obrigando o legislador ordinário, no exercício do seu mister a considerar outros fatores da atividade econômica da empresa como condições de trabalho, número de trabalhadores, benefícios sociais concedidos pelo tomador aos trabalhadores. O artigo 195, $\S 9^{\circ}$ da Constituição Federal indica os elementos para a busca da equidade na forma de participação do custeio.

\subsection{Diversidade da base de financiamento}

A Constituição prevê diversas bases de sustentação do sistema de segurança social, visando-lhe dar segurança e estabilidade. A diversidade de base de financiamento está expressa no artigo 195, caput, incisos I, II, III e IV.

A segurança social será financiada por toda a sociedade de forma direta e indireta, nos termos da lei, mediante recursos provenientes dos orçamentos da União, dos Estados, do Distrito Federal e dos Municípios e das seguintes contribuições sociais: (a) dos empregadores, incidem sobre a folha de salários e demais rendimentos do trabalho pagos ou creditados, a qualquer título, a pessoa física que lhe preste serviço, mesmo sem vínculo empregatício ( $\mathrm{EC}^{\mathrm{o}}$ $20)$, a receita ou o faturamento $\left(E C \mathrm{n}^{\circ} 20\right)$ e o lucro ( $\left.E C \mathrm{n}^{\circ} 20\right)$; (b) dos trabalhadores e demais segurados da previdência social, não incidindo contribuições sobre aposentadorias e pensão concedidas pelo regime geral de previdência social; (c) sobre a receita de concursos de prognósticos; (d) do importador de bens ou serviços ou de quem a lei a ele equiparar.

Caso as bases estabelecidas constitucionalmente para financiamento da seguridade social revelarem-se insuficientes, surge a possibilidade da utilização de um mecanismo de emergência expresso no artigo $195, \S 4^{\circ}$ da $\mathrm{CF} / 1988$, ao preceituar que a lei poderá instituir outras fontes destinadas a garantir a manutenção ou expansão da segurança social, obedecido o disposto no artigo 154, inciso I, da Constituição Federal.

\subsection{Princípio do caráter democrático e descentralizado da gestão do sistema}

Informa o princípio da gestão democrática e descentralizada que a administração dos negócios referentes à segurança social, em todos os seus níveis - desde a fase de planejamento orçamentário (a fase em que se descobre 
o montante de recursos necessários para custear todos os benefícios e serviços), passando pela aplicação desses recursos, chegando até o acompanhamento dos programas -, deve contar com a efetiva participação dos empregados, empregadores, aposentados e do Governo.

\subsection{Princípio da contrapartida ou da precedência de custeio}

Esse princípio é um dos fundamentos do equilíbrio atuarial do sistema de segurança social. Como as receitas são calculadas para atender a despesas previstas, a criação, majoração ou extensão de determinados benefícios ou serviços de saúde, previdência e assistência social devem pressupor a fonte de custeio suficiente para os gastos com tais prestações.

\subsection{Regra nonagesimal ou da trimestralidade na cobrança das contribuições previdenciárias}

O artigo 195, § $6^{\circ}$, da Constituição, estabelece que as contribuições previdenciárias só poderão ser exigidas após decorridos 90 dias da publicação da lei que as houver instituído ou modificado, seja para maior ou menor, não se aplicando o princípio do artigo 150, III, $b$, da Constituição (princípio da anterioridade). O lapso temporal de 90 dias configura a vacatio legis, período que os contribuintes têm para se adentrar às novas exigências da lei de custeio previdenciário. No caso de majoração ou diminuição da alíquota, vige a alíquota anterior até o final do período da vacatio legis.

\section{CONSIDERAÇÕES FINAIS}

O propósito deste artigo foi, em linhas gerais, destacar a ideia de um direito fundamental à segurança social ao evidenciar sua estrutura e seus princípios regentes na ordem constitucional brasileira.

Logo, a segurança social constitui um sistema fixado pela Constituição como instrumento mediante o qual o Estado e toda a sociedade são chamados a concretizar o bem-estar e a justiça sociais. $\mathrm{O}$ bem-estar, harmonizado com a justiça, é assumido como valor dotado de potencial suficiente para transformar a situação social (erradicação da pobreza, da marginalização e da redução das desigualdades sociais) identificada pelo constituinte.

Quando a segurança social, combinação da igualdade com a solidariedade, oferecer correspondente quantia de saúde, de previdência e de assistência a 
todos aqueles que reclamam algum tipo de proteção, conclui-se que o bemestar e a justiça estão concretizados.

A política de proteção social é condição indispensável para a construção de uma sociedade livre, justa e solidária.

\section{REFERÊNCIAS}

ANDRADE, José Carlos Vieira de. Os direitos fundamentais na

Constituição portuguesa de 1976. 5. ed. Coimbra: Almedina, 2012.

BALERA, Wagner. Introdução ao direito previdenciário. São Paulo: LTr, 1998. p. 51.

. Sistema de seguridade social. São Paulo: LTr, 2000.

BANDEIRA DE MELLO, Celso Antônio. Curso de direito

administrativo. 30. ed. rev. e atual. São Paulo: Malheiros, 2013.

BARCELLOS, Ana Paula. O direito a prestações de saúde: complexidades, mínimo existencial e o valor das abordagens coletiva e abstrata. In: SOUZA NETO, Cláudio Pereira de; SARMENTO, Daniel (Org.). Direitos sociais: fundamentos, judicialização e direitos sociais em espécie. Rio de Janeiro: Lumen Juris, 2008. p. 803-826.

CANOTILHO, José Joaquim Gomes; MOREIRA, Vital. Constituição da República Portuguesa anotada. 4. ed. rev. São Paulo: RT; Coimbra, PT: Coimbra Editora, 2007. v. 1.

CUNHA, Luiz Cláudio Flores da. Direito previdenciário: aspectos materiais, processuais e penais. 2. ed. Porto Alegre: Livraria do Advogado, 1999.

HORVATH JÚNIOR, Miguel. Direito Previdenciário. 10. ed. compl. rev. e ampl. São Paulo: Quartier Latin, 2014.

IBRAHIM, Fábio Zambitte. A previdência social como direito fundamental. In: SOUZA NETO, Cláudio Pereira de; SARMENTO, Daniel (Coord.). 
Direitos sociais: fundamentos, judicialização e direitos sociais em espécie. Rio de Janeiro: Lumen Juris, 2008. p. 1053-1082.

LOUREIRO, João Carlos. Direito à (proteção da) saúde. Separata de: Estudos em Homenagem ao Professor Doutor Marcello Caetano no centenário do seu nascimento, Coimbra, p. 657-691, 2006.

. Constituição da segurança social: sujeitos, prestações e princípios. Separata de: Boletim da Faculdade de Direito da Universidade de Coimbra, Coimbra, v. LXXXIV, p. 189-249, 2008.

MARTINEZ, Wladimir Novaes. Curso de direito previdenciário. 3. ed. São Paulo: LTr, 2010.

MENDES, Gilmar Ferreira; BRANCO, Paulo Gustavo Gonet. Curso de direito constitucional. 9. ed. rev, e atual. São Paulo: Saraiva, 2014.

MIRANDA, Jorge; MEDEIROS, Rui. Constituição portuguesa anotada. 2. ed. Coimbra: Coimbra Editora, 2010. v. 1.

NOVAIS, Jorge Reis. Os princípios constitucionais estruturantes da república portuguesa. Coimbra: Coimbra Editora, 2004.

PEDRO, Maria Esther Gómez de. El Estado del Bienestar: presupuestos éticos y políticos. Madrid: Fundación Universitaria Española, 2002.

SARLET, Ingo Wolfgang. A eficácia dos direitos fundamentais. 8. ed. rev. e atual. Porto Alegre: Livraria do Advogado, 2007.

SARLET, Ingo Wolfgang; MARINONI, Luiz Guilherme; MITIDIERO, Daniel. Curso de Direito Constitucional. 3. ed. rev. atual. e ampl. São Paulo: RT, 2014.

TAVARES, Marcelo Leonardo. Assistência social. In: SOUZA NETO, Cláudio Pereira de; SARMENTO, Daniel (Coord.). Direitos sociais: 
fundamentos, judicialização e direitos sociais em espécie. Rio de Janeiro: Lumen Juris, 2008. p. 1123-1139.

Artigo recebido em: 20/12/2014 Aprovado para publicação em: 02/12/2014

Como citar: CARVALHO, Osvaldo Ferreira. O direito fundamental à segurança social e seu panorama na ordem constitucional brasileira. Revista do Direito Público. Londrina, v.10, n.3, p.213-228, set/dez.2015. DOI: 10.5433/1980-511X.2015v10n3p213. ISSN: 1980-511X. 